\title{
ANALISIS PESTISIDA KARBARIL DENGAN METODE KLT- DENSITOMETRI DALAM MATRIKS KEDELAI DAN VALIDASI METODENYA
}

\author{
Sugijantoa*, Prihatin ${ }^{b}$, Noor Erma Sugijanto $\mathrm{Na}^{\mathrm{a}}$ \\ aFakultas Farmasi Universitas Airlangga, \\ bBadan Pengawasan Obat dan Makanan Republik Indonesia \\ *alamat email: ermasugijanto@yahoo.co.id
}

\begin{abstract}
A simple and rapid densitometric method has been developed for determination of low levels of carbaryl in soy bean matrix samples. Sample carbaryl in the soybean matrix was extracted with acetonitril, chloroform and $\mathrm{NaCl} 0.2 \%$ solution, and the resulting chloroform layer was separated, added sodium sulphate anhydrous to get free of water than evaporated. After dissolution in methanol, the solutions were spotted on silica gel $G F_{254}$ plates which were then eluted with toluene: ethyl acetate $=3: 1$ (v/v). Quantitative evaluation was performed by measuring the absorbance reflectance of the analyte spots at $\lambda 280 \mathrm{~nm}$. This densitometric method is selective, precise, accurate and can be used for the determination carbaryl in soy bean matrix.
\end{abstract}

Key words: carbaryl, TLC-densitometry, validation methode, soy bean

\section{PENGANTAR}

Penggunaan pestisida dapat mencegah dan membasmi hama secara efektif dan efisien, namun bila tidak tepat cara pemberian maupun dosisnya dapat menimbulkan dampak merugikan. Karbaril, nama kimianya 1-naftil metilkarbamat merupakan pestisida yang masih dipakai dalam bidang pertanian di beberapa negara termasuk Indonesia dengan nama dagang Sevin, Sekvul atau Carbacide namun di United Kingdom, Austria, Denmark, Swedia, Jerman, dan Angola sudah dilarang penggunaannya. Karbaril suatu kolinesterase inhibitor yang toksik untuk manusia, dan digolongkan karsinogen oleh United States Environmental Protection Agency (EPA) (Anonymus, 2003). WHO dan FAO menetapkan ketentuan tentang batas maksimum residu pestisida pada tiap jenis makanan dan hasil pertanian dan seberapa banyak residu pestisida yang masih dapat diterima perhari (Acceptable daily intake), untuk karbaril $0,001 \mathrm{mg} / \mathrm{kg}$ berat badan (Anonymus, 1986). Dalam hal mengurangi bahaya keracunan pestisida ini perlu dipantau kadar residu karbaril di bahan makanan secara berkala. Mengkaji apakah ketentuan-ketentuan tersebut dilampaui atau tidak, diperlukan suatu metode analisis pestisida karbaril yang tepat, teliti, mempunyai batas deteksi kecil, pelaksanaaannya cepat dan relatif murah.

Beragam metode dapat digunakan untuk analisa karbaril, yaitu kolorimetri (Horwitz, 2000), amperometri (Du et al., 2007), ELISA (Nunes, et al., 1998), flow injectionchemiluminescence (Tsogas et al., 2007), enzimatik- kinetik (Ni et al., 2007), spektrofotometri (Ni et al., 2009), spektrofotometri UV (Cassela et al., 2000), HPLC (Li et al., 2004), LC-MS-MS (Granby et al., 2004 ), dan GC (Shin, et al.,1998). Patil dan Shingare, 1993 melaporkan analisis karbaril dengan metode KLT dengan penampak noda pereaksi fenilhidrazin.

Kromatografi lapis tipis (KLT)-Densitometri merupakan metode analisis yang masih banyak dipakai, karena dapat menganalisis secara kualitatif dan kuantitatif senyawa dalam campuran dengan waktu singkat, relatif sederhana, dan murah, serta mudah dilaksanakan dan dapat digunakan pada kadar kecil (Kantasubrata, 1991). Dalam penelitian ini dikembangkan metode KLT- densitometri yang lebih mudah dan dapat dilakukan dalam waktu singkat menggunakan penampak noda sinar ultra-violet (UV) pada panjang gelombang $280 \mathrm{~nm}$. Suatu metode analisis untuk identifikasi dan kuantitasi senyawa dalam jumlah runutan haruslah mempunyai validasi yang baik, untuk itu tujuan penelitian ini adalah mengkaji validitas metode dalam hal ini sensitivitas, akurasi, dan presisi analisis karbaril dalam matriks kedelai.

\section{BAHAN DAN CARA KERJA}

\section{Bahan}

Karbaril diperoleh dari Sekretariat Komisi Pestisida Bina Perlindungan Tanaman Pangan dan Hortikultura, Dirjen Pertanian dan Tanaman Pangan. Pelarut metanol, asetonitril, kloroform, etil asetat, toluene, benzen, 
$\mathrm{NaCl}$, pelat KLT silicagel $\mathrm{GF}_{254}$ dan $\mathrm{Na}_{2} \mathrm{SO}_{4}$ anhidrous kesemuanya pro analisa dari E.Merck. Kedelai diperoleh dari pasar di Surabaya.

\section{Alat}

Densitometer Shimadzu C-390, neraca analitik, alat kromatografi dan alat gelas.

\section{Preparasi Baku dan Sampel}

Larutan baku dibuat dari 100,0 mg karbaril dilarutkan metanol hingga 100,0 mL, diencerkan hingga diperoleh larutan $10 \mathrm{ppm}$ hingga $500 \mathrm{ppm}$. Sampel pestisida dalam kedelai dibuat dengan cara kedelai diserbuk dan diayak dengan pengayak Mesh 40, ditimbang $25 \mathrm{~g}$ serbuk kedelai dan ditambahkan 2,0 mL larutan karbaril 100 ppm diaduk homogen. Digunakan serbuk kedelai tanpa karbaril sebagai blanko matriks. Replikasi dilakukan tujuh kali dan masingmasing dua kali pengamatan.

\section{Kromatografi}

Kromatografi dilakukan pada pelat KLT silicagel $\mathrm{GF}_{254}$, untuk menotolkan digunakan mikropipet $2 \mu 1$. Disiapkan beberapa sistem pelarut pengembang, yaitu kloroform: benzena $=1: 1(\mathrm{v} / \mathrm{v})$; toluen:etil asetat $=4: 1(\mathrm{v} / \mathrm{v})$ dan $3: 1(\mathrm{v} /$ $\mathrm{v})$; benzena: aseton $=4: 1(\mathrm{v} / \mathrm{v})$, selanjutnya dikembangkan dalam bejana kromatografi Camag (untuk pelat $20 \times 20 \mathrm{~cm}$ ). Noda analit diamati dengan sinar ultra-violet pada panjang gelombang ( $\lambda$ ) $280 \mathrm{~nm}$ dan pereaksi warna anisaldehideasam sulfat. Pengukuran dilakukan dengan Densitometer Shimadzu C-390. Identitas noda ditentukan dengan membandingkan harga $R_{f}$ dan profil spektra ultraviolet pada panjang gelombang 200-370 nm (Gambar 1). Analisis kuantitatif dilakukan dengan mengukur absorbans reflektans noda analit pada panjang gelombang $280 \mathrm{~nm}$.

\section{Analisis Karbaril dalam Sampel}

Serbuk sampel $(25,0 \mathrm{~g})$ diekstraksi dengan $100,0 \mathrm{ml}$ asetonitril, fase asetonitril diambil $50,0 \mathrm{ml}$ lalu diekstraksi dengan dua kali $100 \mathrm{ml}$ kloroform dan $250 \mathrm{ml} \mathrm{NaCl}$ $0,2 \%$. Fase kloroform dikumpulkan dan dibebaskan dari air dengan $\mathrm{Na}$ sulfat anhidrous, diuapkan hingga kering. Residu dilarutkan dalam 1,0 ml metanol ditotolkan 10,0 ul pada pelat KLT, dikembangkan dengan sistem pelarut pengembang terpilih. Noda yang dihasilkan diamati pada

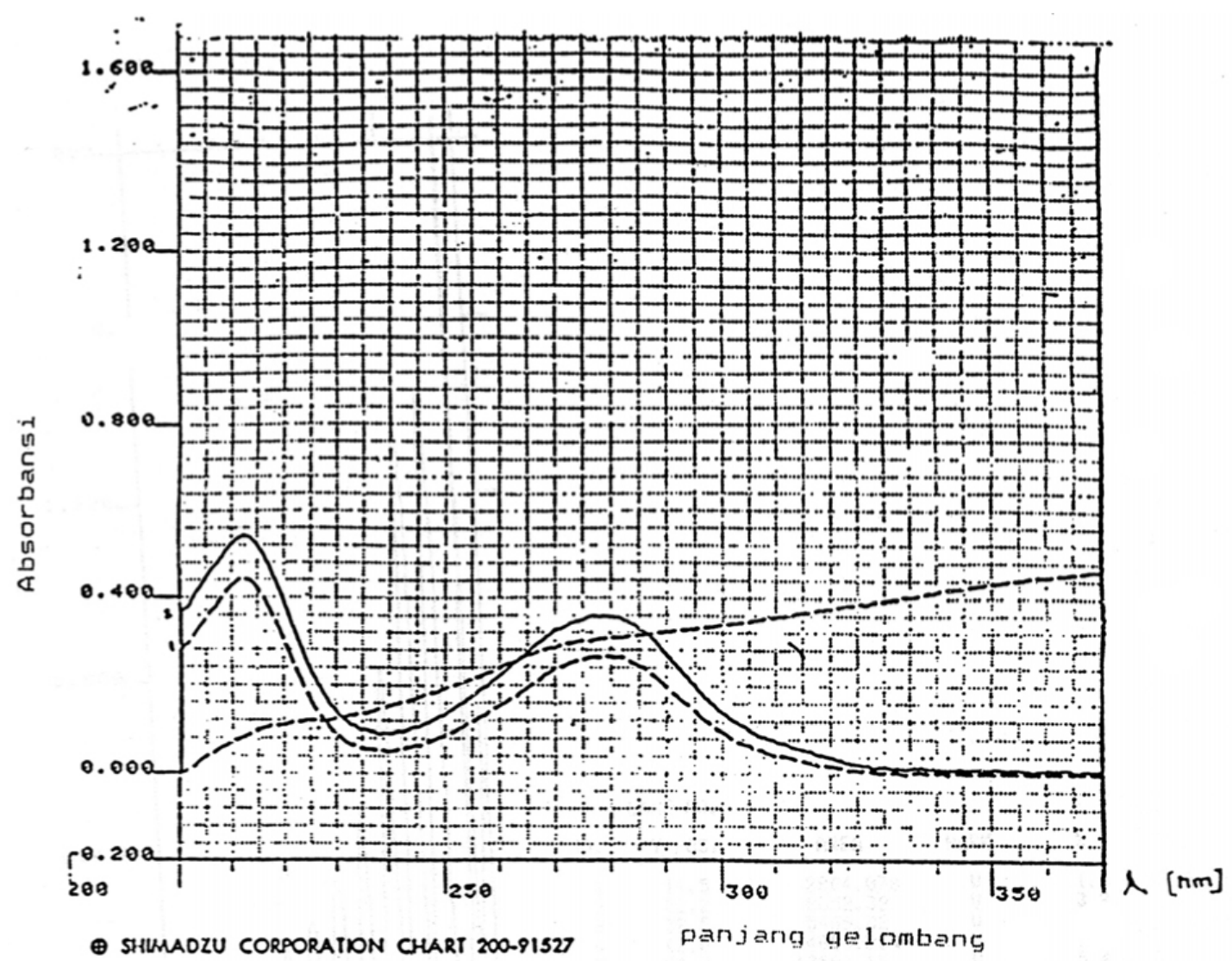

Gambar 1. Profil Spektra ultra violet yang diukur pada $\lambda$ 200-370 nm noda hasil KLT karbaril dari hasil ekstraksi (1) dengan karbaril baku (2) 
Tabel 1. Sistem pelarut pengembang yang digunakan untuk analisis karbaril dalam matriks kedelai

\begin{tabular}{llcc}
\hline No & $\begin{array}{c}\text { Sistem pelarut pengembang } \\
(\mathbf{v} / \mathbf{v})\end{array}$ & Harga $\mathbf{R}_{\mathbf{f}}$ & Harga $\mathbf{R}_{\mathbf{s}}$ \\
\hline 1. & Aseton: benzena $=1: 4$ & 0,16 & 0,87 \\
2. & Toluen : etil asetat $=4: 1$ & 0,28 & 1,22 \\
3. & Toluen : etil asetat $=3: 1$ & 0,39 & 2,35 \\
4. & Kloroform : benzena $=1: 1$ & 0,20 & 0,98 \\
\hline
\end{tabular}

pada panjang gelombang $280 \mathrm{~nm}$ dan diukur luas areanya dengan densitometer.

\section{Validasi Metode}

Metode ini divalidasi linearitas, akurasi, batas deteksi dan batas kuantitasi menurut Funk et al., 1992. Selektivitas metode didapat dengan dengan membandingkan profil spektra UV pada panjang gelombang 200-370 nm (Gambar 1).

\section{HASIL}

Hasil ekstraksi karbaril dalam kedelai ditotolkan pada lempeng silica gel $\mathrm{GF}_{254}$ dengan beberapa sistem pelarut pengembang didapatkan hasil pemisahan seperti disajikan pada Tabel 1. Profil spektrum UV karbaril baku dan dalam sampel ditunjukkan dalam Gambar 1 dengan
Tabel 2. Data pengukuran area dari beberapa kadar larutan baku karbaril

\begin{tabular}{rcr}
\hline No & Kadar (ug) & \multicolumn{1}{c}{ Area } \\
\hline 1. & 0,2009 & 4086,254 \\
2. & 0,2511 & 5469,820 \\
3. & 0,5023 & 8052,390 \\
4. & 1,0046 & 13591,150 \\
5. & 1,5068 & 20141,670 \\
6. & 2,0091 & 25950,070 \\
7. & 2,5114 & 30298,310 \\
8. & 5,0228 & 53008,150 \\
9. & 7,5354 & 85717,600 \\
10. & 10,0056 & 112024,800 \\
\hline
\end{tabular}

panjang gelombang maksimum diperoleh $280 \mathrm{~nm}$. Uji kelurusan diperoleh antara kadar karbaril 0,2-10,0 ug per noda. Persamaan garis regresi yang diperoleh adalah $\mathrm{y}=10894.74 \mathrm{x}+2438,96$ dengan harga $\mathrm{r}=0,9991(\mathrm{n}=10)$. Analisis of variance (ANOVA) uji regresi untuk linearitas diperoleh harga $\mathrm{F}$ hitung 9,0652 dibandingkan terhadap $\mathrm{F}$ tabel pada $\alpha=0,05$ dengan $\mathrm{db}=1 ; 9$, yaitu harga $\mathrm{F}$ tabel $=$ 5,12 dalam hal ini $\mathrm{F}$ hitung $>\mathrm{F}$ tabel berarti ada hubungan linier yang bermakna antara kadar karbaril dengan area. Kurva linieritas disajikan pada Gambar 2. Data area dengan kadar larutan karbaril, disajikan di Tabel 2. Berdasarkan

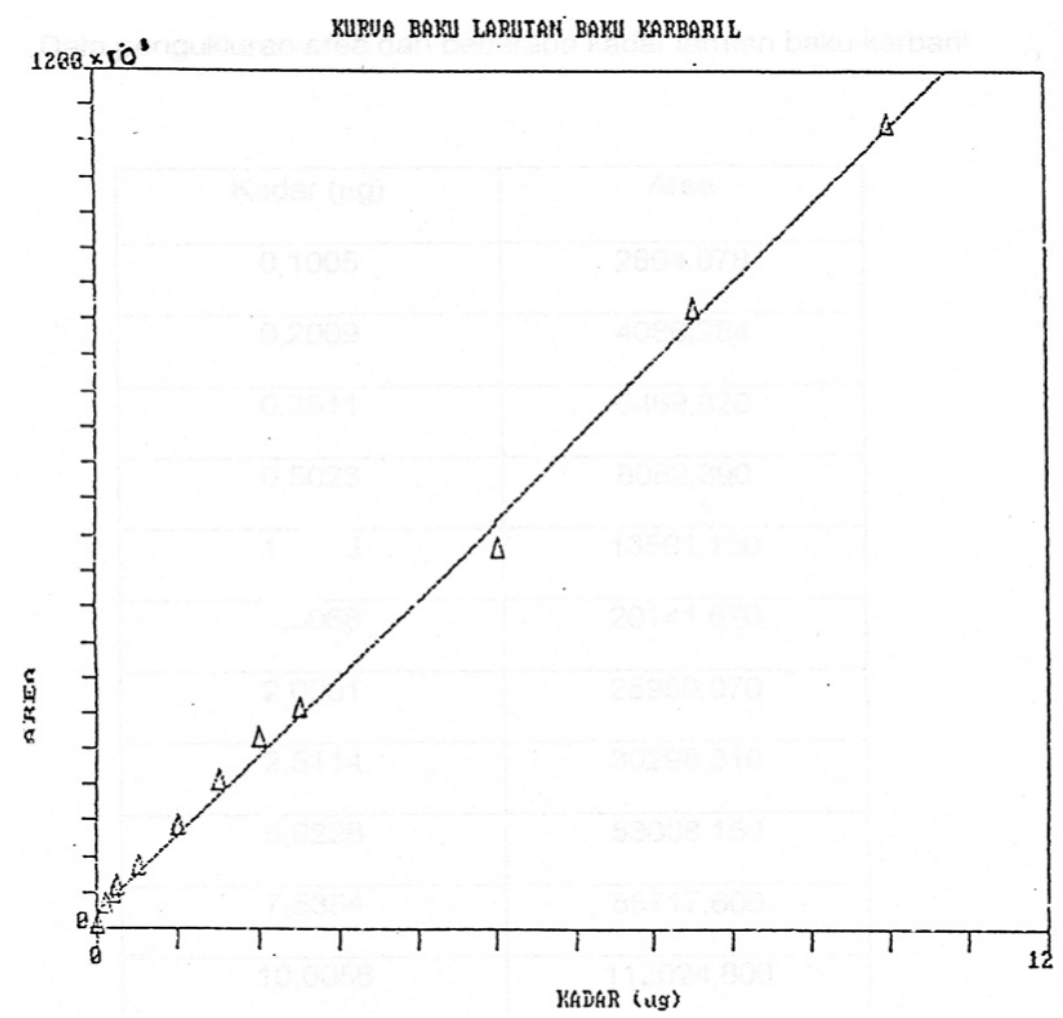

Gambar 2. Kurva baku karbaril antara kadar karbaril 0,2 ug-10,0 ug per noda. Persamaan garis regresi yang diperoleh adalah y $=$ 10894.74x + 2438,96 dengan harga $r=0,9991(n=10)$. 
perhitungan persamaan garis regresi kurva linier didapatkan harga slope 10894,74 sedang dengan metode Carr dan Wahrlich, 1990 diperoleh batas deteksi 0,055 ug dan batas kuantitasi 0,183 ug.

\section{PEMBAHASAN}

Ekstraksi karbaril dalam sampel menurut Horwitz, 2000 digunakan diklormetan-petroleum eter, namun Prihartomo melaporkan untuk analisis pestisida golongan karbamat jenis karbaril dan karbofuran dalam kedelai digunakan asetonitril-diklormetan-petroleum eter hasilnya lebih baik (Prihartomo, 1994). Dalam penelitian ini digunakan asetonitril-kloroform dan terbukti hasilnya cukup baik dengan perolehan kembali di atas $80 \%$ sehingga memenuhi persyaratan untuk analisa sampel dalam matriks biologis (Yuwono and Indrayanto, 2005).

Metode analisis dengan kromatografi dikatakan selektif bila harga $\mathrm{R}_{\mathrm{s}}$ yaitu keterpisahan antara dua noda lebih dari 1,5 dan dalam KLT harga $R_{\mathrm{f}}$ yang baik adalah antara 0,2 hingga 0,8 (Touchstone \& Dobbins, 1983). Dalam hal ini dipilih sistem pelarut pengembang, toluen : etil asetat $=3: 1(\mathrm{v} / \mathrm{v})$ karena diperoleh hasil pemisahan komponen analit yang baik dengan harga $R_{\mathrm{f}}$ karbaril 0,39 memenuhi syarat $0,2-0,8$. Noda karbaril terpisah dengan baik dari dua noda senyawa endogen kedelai dengan $R_{f} 0,10$ dan 0,23 dengan harga $R_{s} 2,35$ sehingga memenuhi juga syarat resolusi yang $>1,5$ (Yuwono \& Indrayanto, 2005). Hasil kromatografi lapis tipis sampel di samping noda karbaril terdapat dua noda lain yang belum diketahui, kemungkinan pestisida lain atau senyawa endogen kedelai yang ikut terekstraksi dan terpisahkan/tereluasi. Noda karbaril sampel dibandingkan harga $\mathrm{R}_{\mathrm{f}}$ dan panjang gelombang maksimumnya dengan baku karbaril diperoleh profil spektrum UV yang identik dengan panjang gelombang maksimum pada $280 \mathrm{~nm}$, yang selanjutnya digunakan pada pengukuran secara densitometri. Dipilih panjang gelombang maksimum dalam analisis intensitas noda dari senyawa tersebut karena pada panjang gelombang tersebut merupakan absorpsi zat yang paling besar dan kesalahan pengukuran akan lebih kecil, sehingga diperoleh hasil yang lebih teliti.

Hasil penetapan kadar karbaril dalam sampel kedelai dengan tujuh kali replikasi didapatkan perolehan kembali antara $83,36 \%$ hingga $96,24 \%$ dengan perolehan rata-rata $(88,81 \pm 4,03) \%$, presisinya diperoleh harga koefisien variasi (KV) 4,53\%. Hal ini memenuhi persyaratan Moye yaitu perolehan kembali di atas $85 \%$ dengan presisi $10 \%$ sedang menurut Skoog presisi yang baik untuk metode KLT densitometri tidak lebih dari 5\%, sementara presisi untuk sampel dalam matriks biologis dapat diterima hingga 10-15\% (Yuwono \& Indrayanto, 2005). Kedua persyaratan tersebut dapat dipenuhi dengan sensitivitas yang cukup kecil yaitu batas deteksi 0,055 ug dan batas kuantitasi 0,183 ug maka metode ini dapat disarankan sebagai metode alternatif bagi penetapan kadar karbaril dalam sampel makanan atau matriks biologis selain menggunakan spektrofotometri, kromatografi gas dan kromatografi cair kinerja tinggi.

Berdasarkan hasil penelitian dan pembahasan di atas, disimpulkan bahwa analisis karbaril secara KLTdensitometri ini selektif, akurat dengan presisi yang baik, dapat digunakan untuk penentuan karbaril pada kadar rendah dalam matriks bahan makanan.

Diharapkan metode penentuan kadar karbaril dalam kedelai dengan cara KLT-densitometri ini, dapat digunakan sebagai metode alternatif yang lebih sederhana dan lebih rendah biayanya daripada kromatografi gas dan kromatografi cair kinerja tinggi.

\section{KEPUSTAKAAN}

Anonymus, 1986. Carbamate pesticide a general introduction, WHO Environmental Health Criteria 64, Geneva 20-23, 63-64, 121.

Anonymus, 2003. Wikipedia the free encyclopedia, Wikipedia Foundation Inc. Tgl diakses 23 April 2009.

Cassella RJ, Garrigues S, Santelli RE, and Guardia M, 2000, Spectrophotometric determination of carbaryl by on-line elution after its preconcentration onto polyurethane foam, Talanta, 52: 717-725.

Carr GP and Wahlich J, 1990. A practical approach to methods validation in pharmaceutical analysis. Journal of Pharmaceutical and Biomedical Analysis, 8: 613-618.

Du D, Ding J, Cai J, dan Zhang A, 2007. Determination of carbaryl pesticide using amperometric acetylcholinesterase sensor formed by electrochemically deposited chitosan, Colloids and Surfaces, 58: 145-150

Funk W, Damman V, and Donnervert G, 1992. Qualititätssicherung in der analytischen chemie VH, Weinheim 12-36, 161-180.

Granby K, Andersen JH, dan Christensen HB, 2004. Analysis of pesticides in fruit, vegetables and cereals using methanolic extraction and detection by liquid chromatographytandem mass spectrometry, Analytica Chimica Acta, 520: 165-176.

Horwitz W (Eds), 2000. Official methods of analysis of AOAC International, 17 th edition, vol. 1, chapter 10, Agricultural Chemicals; Contaminants; Drugs, The Scientific Association, 5-7, 46-48.

Kantasubrata J, 1991. Warta Kimia Analitik, Puslitbang Kimia Terapan LIPI, 9: 4-7.

Li HP, Li JH, Li GC, dan Jen JF, 2004. Simultaneous determination of airborne carbamates in workplace by high performance liquid chromatography with fluorescence detection, Talanta, 63: 547-553. 
Moye HA, 1995. Analysis of pesticides residues. John Wiley and sons, New York, 333-444.

Ni Y, Cao DX, dan Kokot S, 2007. Simultaneous enzymatic kinetic determination of pesticides, carbaryl and phoxim, with the aid of chemometrics, Analytica Chimica Acta, 588: 131-139.

Ni Y, Xiao W, dan Kokot S, 2009. Application of chemometrics methods for the simultaneous kinetic spectrophotometric determination of aminocarb and carbaryl in vegetable and water samples, Journal of Hazardous Materials, 168: 1239-1245.

Nunes GS, Marco MP, Ribeiro ML, Barcelo D, 1998. Validation of an immunoassay method for the determination of traces of carbaryl in vegetable and fruit extracts by liquid chromatography with photodiode array and mass spectrometric detection, J. of Chromatography, 823: 109-120.

Patil VB dan Shingare MS, 1993. Thin-layer chromatographic detection of carbaryl using phenylhydrazine hydrochloride, J. of Chromatography, 653: 181-183.

Prihartomo T, 1994. Analisis residu pestisida karbaril dan karbofuran pada biji kedelai mentah pasca panen, unpublished research.
Shin YS, Ko M, dan Shin HS, 1998. Simultaneous quantification of insecticides including carbaryl in drinking water by gas chromatography using dual electron-capture and nitrogen-phosphorus detection, J. of Chromatography, 769: 285-291.

Skoog D and West A, 1980. Principles of instrumental analysis $2^{\text {nd }}$ ed., Saunders College, Philadelphia, 837-847.

Tsogas GZ, Giokas DL, Nikolakopoulos PG, Vlessidis AG, dan Evmiridis NP, 2005, Determination of the pesticide carbaryl and its photodegradation kinetics in natural waters by flow injection-direct chemiluminescence detection, Analytica Chimica Acta, 573-574: 354-359.

Touchstone JC and Dobbins MF, 1983. Practice of Thin Layer Chromatography. A Wiley Interscience Publication, New York, 102-136.

Yuwono M and Indrayanto G, 2005. Validation method of analysis by using Chromatography, Profiles of Drugs Substances, Excipients and Related Methodology, Vol. 32, Elsevier Academic Press, San Diego, New York, Boston, London, Sydney, Tokyo, Toronto. 243-258.

Reviewer: Dr. Nanik Siti Aminah 